\title{
SUBSTITUIÇÃO DA CAPTAÇÃO DOS DADOS DO CAGED PELO ESOCIAL: IMPLICAÇÕES PARA AS ESTATÍSTICAS DO EMPREGO FORMAL ${ }^{1,2}$
}

\author{
Mariana Eugenio Almeida ${ }^{3}$ \\ Tamille Sales Dias ${ }^{4}$ \\ Rosângela Jardim de Farias ${ }^{5}$ \\ Augusto Veras Soares Martinez Albuquerque ${ }^{6}$ \\ Sergio Luiz Rodrigues Torres ${ }^{7}$ \\ Luis Felipe Batista de Oliveira ${ }^{8}$
}

\section{INTRODUÇÃO}

A Portaria da Secretaria Especial de Previdência e Trabalho do Ministério da Economia (SEPRT/ ME) nº 1.127, de 14 de outubro de 2019, definiu as datas e as condiçóes nas quais as obrigaçóes de prestação de informações pelo empregador nos sistemas Cadastro Geral de Empregados e Desempregados (Caged) e Relação Anual de Informações Sociais (Rais) serão substituídas pelo Sistema de Escrituração Digital das Obrigaçôes Fiscais, Previdenciárias e Trabalhistas (eSocial), instituído pelo Decreto ํㅡㄹ 8.373, de 11 de dezembro de 2014 .

Nesse contexto, esta nota técnica trata da análise e das consideraçôes sobre o impacto dessa substituição, em especial na geração das estatísticas mensais do emprego formal provenientes do Caged.

\subsection{Sobre o Caged}

O Caged foi criado pela Lei no 4.923, de 23 de dezembro de 1965, como instrumento de acompanhamento e de fiscalização dos processos de admissão e dispensa de trabalhadores regidos pela Consolidaçáo das Leis Trabalhistas (CLT). Originalmente criado para fins operacionais, o Caged constitui hoje importante fonte de informação sobre o mercado de trabalho formal, tanto pela abrangência das informaçóes captadas como pela tempestividade e riqueza dos dados. A SEPRT/ME mantém um sistema de consulta aos dados do Caged para comprovação de vínculos dos trabalhadores e possui, desde 1987, o Programa de Disseminação das Estatísticas do Trabalho (PDET), que tem como objetivo divulgar informações estatísticas oriundas dos registros administrativos à sociedade.

1. DOI: http://dx.doi.org/10.38116/bmt69/notastecnicas3

2. A Secretaria de Trabalho agradece as contribuições dos seguintes pesquisadores: Aguinaldo Maciente, André Portela, Carlos Henrique Corseuil, Cimar Azeredo, Francisco Marta, Vinícius Fonseca, Fabiano Giovanini, Gustavo Gonzaga e Sérgio Firpo. As opiniões emitidas e as decisões reportadas nesta nota são de exclusiva e inteira responsabilidade da Secretaria de Trabalho.

3. Coordenadora-geral de cadastros, identificação profissional e estudos na Secretaria de Trabalho do Ministério da Economia.

4. Coordenadora de estatísticas e estudos do trabalho na Secretaria de Trabalho/Ministério da Economia.

5. Coordenadora de cadastros administrativos na Secretaria de Trabalho/Ministério da Economia.

6. Consultor do Banco Interamericano de Desenvolvimento (BID) na Secretaria de Trabalho/Ministério da Economia.

7. Economista na Secretaria de Trabalho/Ministério da Economia.

8. Assessor na Secretaria de Trabalho/Ministério da Economia. 


\subsection{Sobre o eSocial}

O eSocial foi instituído pelo Decreto no 8.373/2014, com o objetivo de unificar e simplificar a prestação de informaçóes relativas a trabalhadores e empresas, bem como o cumprimento de obrigaçóes fiscais, previdenciárias e trabalhistas.

Conforme disposto na Portaria no 300, de 13 de junho de 2019, a gestáo do eSocial é exercida de maneira compartilhada entre a SEPRT e a Secretaria Especial da Receita Federal do Brasil (RFB), ambas integrantes do ME, às quais compete, entre outras atribuiçóes, estabelecer diretrizes gerais, formular políticas referentes ao eSocial, estabelecer o calendário de substituição das obrigaçóes de entrega de informaçóes prestadas em outras declaraçóes e promover a simplificação do sistema. Também integra o projeto o Instituto Nacional do Seguro Social (INSS).

A implantação do eSocial elimina a redundância nas informaçóes prestadas pelas pessoas físicas e jurídicas e apresenta a oportunidade de aprimorar a qualidade das informaçóes trabalhistas, previdenciárias e tributárias. $\mathrm{O}$ sistema se propóe a substituir ao menos treze obrigaçóes ${ }^{9}$ acessórias dos empregadores, reunindo-as em canal único.

Dada a magnitude e complexidade do projeto, a implantação do eSocial está sendo realizada em etapas. Para tanto, os empregadores foram divididos em grupos que possuem prazos distintos para o início da obrigatoriedade de utilização do sistema. O cronograma vigente foi definido pela Portaria SEPRT/ME no 1.419 , de 23 de dezembro de $2019,{ }^{10}$ conforme descrito no quadro 1 .

QUADRO 1

Cronograma de implantação do eSocial

\begin{tabular}{|l|l|l|}
\hline Grupo & \multicolumn{1}{|c|}{ Descrição } & \multicolumn{1}{|c|}{$\begin{array}{c}\text { Início da obrigatoriedade } \\
\text { ao eSocial }\end{array}$} \\
\hline 1 & $\begin{array}{l}\text { Entidades empresariais com faturamento acima de R\$ 78 milhões em 2016. } \\
\text { Demais entidades empresariais, exceto os optantes pelo Simples Nacional, que } \\
\text { constam nessa situação no Cadastro Nacional de Pessoa Jurídica (CNPJ), em } \\
1 \text { o- de julho de 2018, ou que não fizeram essa opção quando de sua constituição, } \\
\text { se posterior. }\end{array}$ & Julho de 2018 \\
\hline 3 & $\begin{array}{l}\text { Entidades empresariais optantes pelo Simples Nacional, microempreendedores in- } \\
\text { dividuais (MEI), empregadores pessoa física (exceto domésticos) e entidades sem } \\
\text { fins lucrativos. }\end{array}$ & Janeiro de 2019 \\
\hline 4 & $\begin{array}{l}\text { Entes públicos de âmbito federal, organizações internacionais e outras instituições } \\
\text { extraterritoriais. }\end{array}$ & Setembro de 2020 \\
\hline 5 & $\begin{array}{l}\text { Entes públicos de âmbito estadual e Distrito Federal. } \\
\text { Entes públicos de âmbito municipal, comissões polinacionais e consórcios públicos. }\end{array}$ & Novembro de 2021 \\
\hline 6 & Enril de 2021 \\
\hline
\end{tabular}

Fonte: Brasil (2019b).

Elaboração dos autores.

9. Cada obrigação possui um cronograma próprio de substituição pelo eSocial. Para fins de análise nesta nota técnica, considera-se apenas o processo de substituição do Caged pelo eSocial. Mais informaç̧̃̃es sobre as obrigações que serão substituídas pelo eSocial estão disponíveis em: <https://bit.ly/3ei2a8e> .

10. Os prazos anteriores à Portaria no 1.419/2019 foram definidos por outros normativos e estão disponíveis em: <https://bit. ly/3ec7PNi>. 
Em outubro de 2019, a SEPRT/ME publicou a Portaria no 1.127/2019 que definiu as datas e condiçôes nas quais a obrigação de prestação de informações pelo empregador no sistema do Caged será substituída pelo eSocial. A figura 1 apresenta a linha do tempo da obrigatoriedade ao eSocial e da desobrigação do Caged.

FIGURA 1

Linha do tempo do eSocial: início da obrigatoriedade de envio das informações de admissões e desligamentos para cada grupo de empregadores

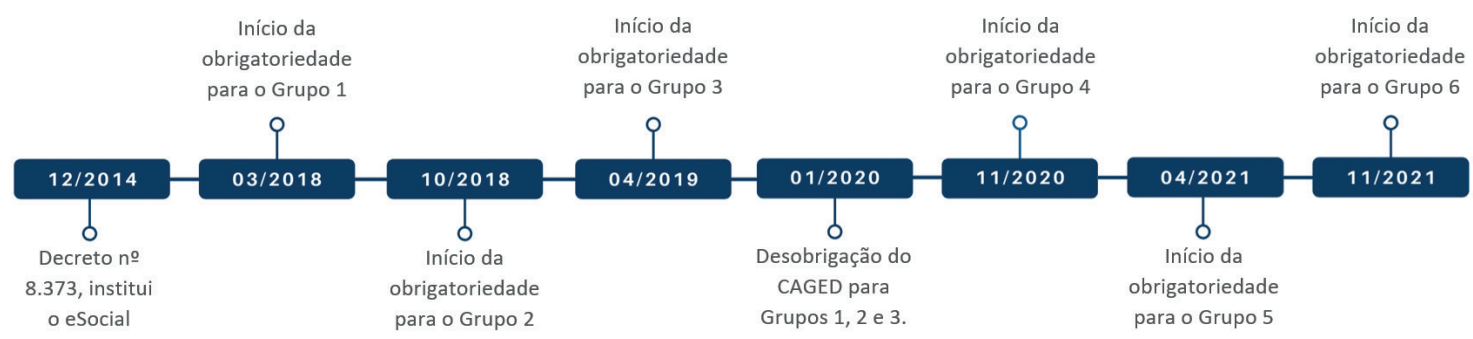

Fonte: Brasil (2019a; 2019b).

Elaboração dos autores.

Obs.: Figura cujos leiaute e textos não puderam ser padronizados e revisados em virtude das condições técnicas dos originais (nota do Editorial).

\section{DIFERENÇAS METODOLÓGICAS ENTRE 0 CAGED E 0 ESOCIAL}

O quadro 2 sintetiza as principais diferenças metodológicas entre o Caged e o eSocial, que devem ser consideradas para fins de análise estatística dos dados. Inicialmente, cabe destacar que o Caged foi criado com finalidade trabalhista, enquanto o eSocial possui caráter tributário, previdenciário e trabalhista. Essa diferença de propósito pronuncia-se igualmente na natureza distinta dos sistemas e no comportamento das empresas quando de suas declaraçóes.

Observa-se, assim, que o eSocial capta um volume de informaçóes mais amplo que o Caged. Mais especificamente no que diz respeito às informaçóes trabalhistas, cabe destacar os campos quem deve declarar e quem deve ser declarado detalhados no quadro $2 .{ }^{11}$

Durante o período de transição, no entanto, para fins de consolidação das estatísticas e compatibilização de série histórica, estão sendo consideradas do eSocial apenas aquelas informaçóes que devem ser declaradas no Caged. Uma diferença fundamental entre os dois sistemas é que a declaração dos vínculos temporários no Caged é opcional, enquanto no eSocial é obrigatória. Como não é possível identificar os vínculos temporários no Caged (eles são contabilizados como empregados celetistas), foi feita uma análise a partir dos dados da Rais 2017 e 2018, que mostrou que apenas 17\% dos vínculos temporários foram informados no Caged nesses mesmos anos. Dessa forma, entendese que o volume de movimentaçôes no eSocial, na média, tende a ser superior àquelas verificadas historicamente no Caged, uma vez que neste sistema os vínculos temporários são subdeclarados.

11. Para informações detalhadas sobre a forma de captação dos dados do Caged e do eSocial, indicamos consulta aos manuais de declaração, disponíveis em: <https://bit.ly/2BVyAbt> e <https://bit.ly/38JRjmi>. 
Outra diferença fundamental é que, no Caged, a obrigatoriedade do envio da informação é do estabelecimento, enquanto no eSocial é da empresa. No entanto, no eSocial, a empresa deve prestar as informaçóes de cada um de seus estabelecimentos, possibilitando que os dados sejam consolidados em nível de estabelecimento, assim como no Caged.

\section{QUADRO 2}

\section{Diferenças metodológicas entre o Caged e o eSocial}

\begin{tabular}{|c|c|c|}
\hline Característica & Caged & eSocial \\
\hline Finalidade & Trabalhista. & Trabalhista, previdenciária e tributária. \\
\hline $\begin{array}{l}\text { Responsável pela prestação } \\
\text { da informação }\end{array}$ & Estabelecimento. & Empresa. \\
\hline Periodicidade de captação & $\begin{array}{l}\text { Diário para admissões de trabalhadores em } \\
\text { percepção do seguro-desemprego e mensal } \\
\text { para demais admissões e desligamentos, com } \\
\text { prazo até o sétimo dia do mês subsequente. }\end{array}$ & $\begin{array}{l}\text { Diário para todas as admissões e para todos os } \\
\text { desligamentos - parte em até dez dias e parte até } \\
\text { o fechamento da folha de pagamento no 150 dia } \\
\text { do mês subsequente. }\end{array}$ \\
\hline $\begin{array}{l}\text { Captação de declarações } \\
\text { fora do prazo }\end{array}$ & Até doze meses após a movimentação. & Sem limitação. \\
\hline Periodicidade de divulgação & Mensal. & Mensal. \\
\hline Quem deve declarar & $\begin{array}{l}\text { Todo estabelecimento formal que tenha efe- } \\
\text { tuado qualquer tipo de movimentação em seu } \\
\text { quadro de empregados, incluindo empresas e } \\
\text { órgãos públicos. }{ }^{1}\end{array}$ & $\begin{array}{l}\text { Todo aquele que contratar prestador de serviço } \\
\text { pessoa física e possua alguma obrigação trabalhis- } \\
\text { ta, previdenciária ou tributária, em função dessa } \\
\text { relação jurídica de trabalho. }{ }^{2} \\
0 \text { obrigado poderá figurar como empregador, nos } \\
\text { termos definidos pelo art. } 2^{\circ} \text { da CLT ou como contri- } \\
\text { buinte, conforme delineado pela Lei no } 5.172 / 1966 \\
\text { (Código Tributário Nacional - CTN), na qualidade } \\
\text { de empresa, inclusive órgão público, ou de pessoa } \\
\text { física equiparada a empresa, conforme prevê o art. } \\
15 \text { da Lei no } 8.212 / 1991 \text {. } \\
\text { Estão obrigados ainda os contribuintes que adqui- } \\
\text { rem ou comercializarem produção rural. } \\
\text { Também determinados contribuintes na situação } \\
\text { Sem Movimento. }\end{array}$ \\
\hline Quem deve ser declarado 3 & $\begin{array}{l}\text { Empregados contratados por empregadores, } \\
\text { pessoa física ou jurídica, sob o regime da CLT, } \\
\text { por prazo indeterminado ou determinado, in- } \\
\text { clusive a título de experiência, ou para presta- } \\
\text { ção de trabalho intermitente; } \\
\text { trabalhadores com contrato de trabalho por } \\
\text { prazo determinado, regido pela Lei no } 9.601 \text {, } \\
\text { de } 21 \text { de janeiro de 1998; } \\
\text { trabalhadores regidos pelo Estatuto do Traba- } \\
\text { lhador Rural (Lei no } 5.889 \text {, de } 8 \text { de junho de } \\
\text { 1973); } \\
\text { aprendizes (maiores de 14 anos e menores de } \\
24 \text { anos), contratados nos termos do art. } 428 \\
\text { da CLT, regulamentado pelo Decreto no } 5.598, \\
\text { de 10 de dezembro de } 2005 \text {; } \\
\text { trabalhadores temporários, regidos pela Lei no } \\
6.019 \text {, de } 3 \text { de janeiro de } 1974 \text {, e alterações } \\
\text { (opcional); e } \\
\text { novas categorias criadas na modernização } \\
\text { trabalhista, Lei no } 13.467, \text { de } 13 \text { de julho de } \\
2017 \text {. }\end{array}$ & $\begin{array}{l}\text { Empregados sob o regime CLT; } \\
\text { trabalhadores temporários; } \\
\text { trabalhadores avulsos; } \\
\text { agentes públicos; } \\
\text { trabalhadores cedidos e dirigentes sindicais; } \\
\text { contribuintes individuais; e } \\
\text { bolsistas. }\end{array}$ \\
\hline
\end{tabular}




\begin{tabular}{|c|c|c|}
\hline Característica & Caged & eSocial \\
\hline $\begin{array}{l}\text { Quem não deve ser decla- } \\
\text { rado }\end{array}$ & $\begin{array}{l}\text { Servidores da administração pública direta ou } \\
\text { indireta, federal, estadual ou municipal, bem } \\
\text { como das fundações supervisionadas; } \\
\text { trabalhadores avulsos; } \\
\text { diretores sem vínculo empregatício; } \\
\text { servidores públicos não efetivos; } \\
\text { dirigentes sindicais; } \\
\text { autônomos; } \\
\text { eventuais; } \\
\text { ocupantes de cargos eletivos; } \\
\text { estagiários; } \\
\text { empregados domésticos residenciais; } \\
\text { cooperados ou cooperativados; } \\
\text { trabalhadores com contrato de trabalho por } \\
\text { prazo determinado, regido por lei estadual ou } \\
\text { municipal; e } \\
\text { trabalhadores com contrato de trabalho por } \\
\text { tempo determinado, regido pela Lei no } 8.745 \text {, } \\
\text { de } 9 \text { de dezembro de } 1993 \text {, com a redação } \\
\text { dada pela Lei no } 9.849 \text {, de } 26 \text { de outubro de } \\
1999 \text {. }\end{array}$ & $\begin{array}{l}\text { Todos os trabalhadores formais devem prestar } \\
\text { informações ao eSocial. }\end{array}$ \\
\hline Abrangência na divulgação & $\begin{array}{l}\text { Brasil, Unidades da Federação (UFs) e municí- } \\
\text { pios. }\end{array}$ & Brasil, UFs e municípios. \\
\hline $\begin{array}{l}\text { Penalidades pelo não cum- } \\
\text { primento da obrigação }\end{array}$ & $\begin{array}{l}\text { Valores por empregado: } \\
\mathrm{R} \$ 4,47 \text { (até } 30 \text { dias de atraso); } \\
\mathrm{R} \$ 6,70 \text { (de } 31 \text { a } 60 \text { dias de atraso); e } \\
\mathrm{R} \$ 13,40 \text { (acima de } 60 \text { dias de atraso). }\end{array}$ & $\begin{array}{l}0 \text { empregador está sujeito às mesmas penalida- } \\
\text { des anteriormente aplicadas por cada obrigação } \\
\text { descumprida. A não declaração de admissões e } \\
\text { demissões, por exemplo, poderá acarretar pena- } \\
\text { lidades administrativas relacionadas às faltas de: } \\
\text { registro de empregados; anotação na Carteira de } \\
\text { Trabalho e Previdência Social (CTPS); e declara- } \\
\text { ção do Caged ou da Rais, fundamentadas nos } \\
\text { mesmos normativos e com os mesmos valores } \\
\text { anteriores. }\end{array}$ \\
\hline
\end{tabular}

Elaboração dos autores.

Notas: ${ }^{1}$ Os estabelecimentos declarantes podem ser do tipo CNPJ, Cadastro Específico do INSS (CEI) ou Cadastro de Atividade Econômica da Pessoa Física (CAEPF).

${ }^{2}$ Os empregadores declarantes podem ser do tipo CNPJ ou Cadastro de Pessoas Físicas (CPF). Os estabelecimentos podem ser desagregados por CNPJ, Cadastro Nacional de Obras (CNO) ou CAEPF.

Obs.: Para detalhamento das categorias de trabalhadores que devem ser informadas no Caged e no eSocial, ver documentação técnica dos sistemas disponível em: <https://bit.ly/3efaPsj> e $<$ https://bit.ly/3fh8aPX>.

\subsection{Análise da viabilidade de compatibilização da série histórica do Caged e do eSocial}

Conforme o cronograma do eSocial apresentado anteriormente, as empresas do grupo 1 passaram a utilizar o sistema desde janeiro de 2018. Tendo em vista que os normativos do Caged ainda estavam vigentes, tais empresas estavam cumprindo as obrigaçóes tanto por meio do eSocial quanto pelo Caged. Nesse período de transição, a SEPRT/ME vem mantendo paralelamente a captação dos dados do Caged e do eSocial, o que permitiu a geração de uma série para a comparação entre os dois sistemas e possibilitou realizar análises quanto à viabilidade de compatibilização dos dados oriundos das duas fontes, bem como ao comportamento das empresas nos sistemas. Dessa forma, propõe-se um exercício analítico de comparação entre as informaçóes captadas de ambas as fontes. 
Os gráficos 1, 2 e 3 mostram a análise realizada com os dados do Caged e do eSocial ao longo de 2019. Para esse exercício analítico, foram considerados os dados desde abril, data em que as empresas passaram a ser obrigadas a enviar as informaçôes de admissôes e desligamentos. A série de dados do eSocial é híbrida, visto que inclui também as informaçóes prestadas pelas empresas dos grupos 4, 5, 6 e pelos órgãos públicos ao Caged (grupos não obrigados ao eSocial). A composição da série considerou os seguintes critérios:

- as informaçôes de movimentaçóes de vínculos celetistas provenientes do eSocial para as empresas dos grupos 1, 2 e 3;

- as informações de movimentaçôes de vínculos celetistas provenientes do Caged para os órgáos públicos e entidades dos grupos 4, 5 e 6;

- as informaçóes prestadas ao eSocial, na hipótese de a empresa ter prestado informaçóes em duplicidade, relativas ao mesmo período, tanto para o eSocial quanto para o Caged;

- as informaçóes do Caged quando a empresa não prestou informação ao todas as variáveis foram compatibilizadas mantendo-se o mesmo layout do Caged.

Assim, pôde-se reconstruir uma série para o período de abril a dezembro de 2019 utilizando o eSocial como base prevalente na captação das informaçóes. Os gráficos 1 e $2^{12}$ apresentam a quantidade de admissóes e desligamentos captados por ambos os sistemas. No que se refere às admissóes, verificou-se que os valores encontrados no eSocial foram superiores aos do Caged em todos os meses do período. Já no que se refere aos desligamentos, os valores encontrados no eSocial foram bem próximos ou inferiores àqueles encontrados no Caged, com exceção de dezembro de 2019.

\section{GRÁFICO 1}

\section{Quantidade de admissões no Caged e no eSocial (abr./2019-dez./2019)}

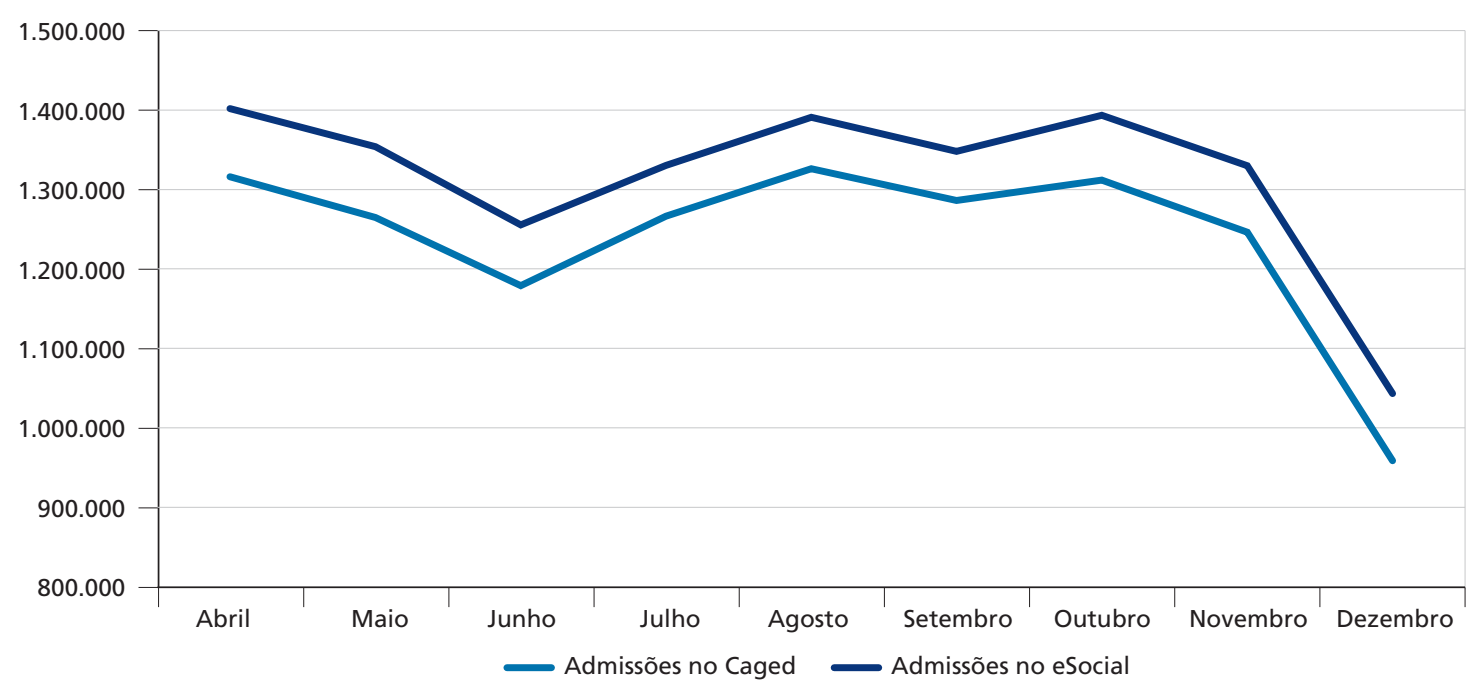

Fontes: eSocial; e Caged. Disponível em: <http://pdet.mte.gov.br/>.

12. Os dados detalhados podem ser consultados no anexo $A$. 


\section{GRÁFICO 2}

Quantidade de desligamentos no Caged e no eSocial (abr./2019-dez./2019)

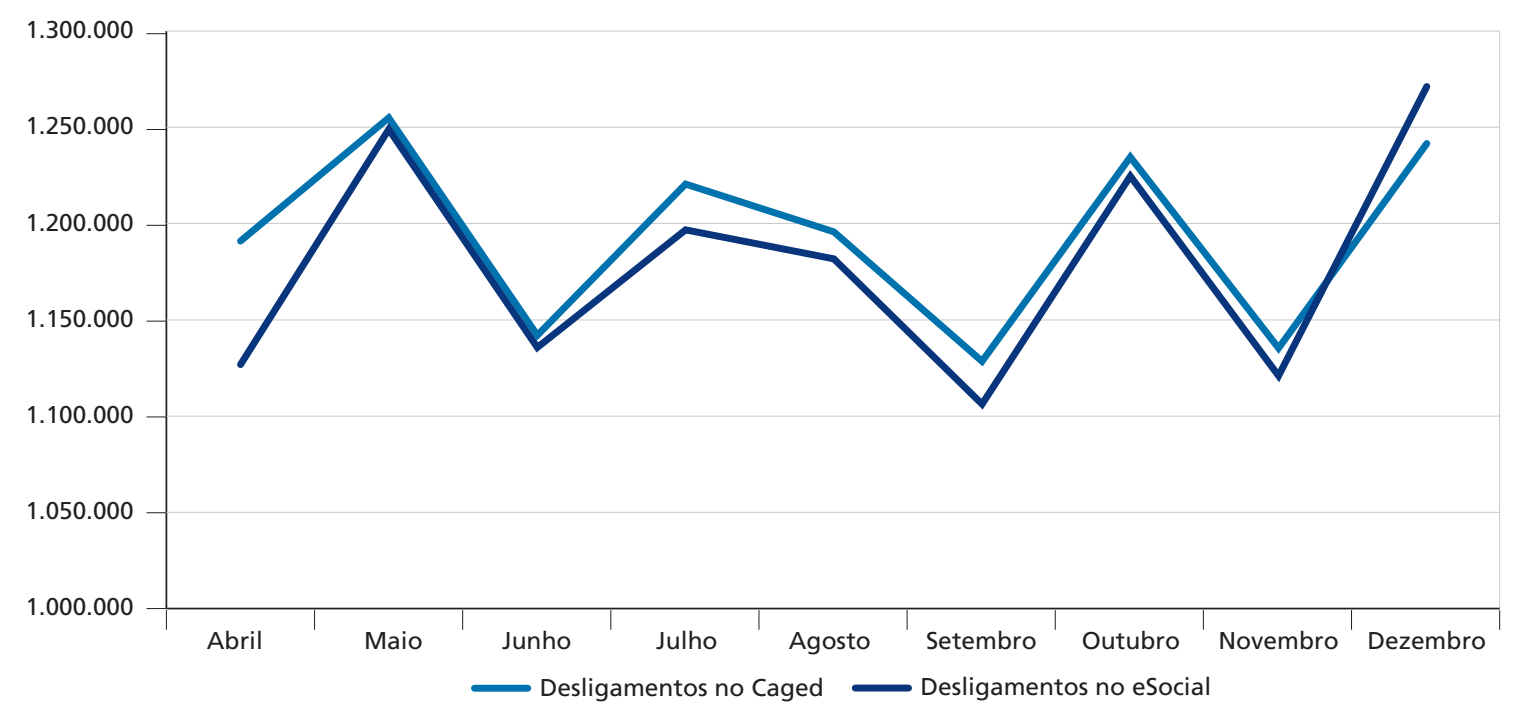

Fontes: eSocial; e Caged. Disponível em: <http://pdet.mte.gov.br/>.

Quanto às diferenças observadas, o resultado das admissóes mostra que, em termos absolutos, o volume de movimentaçóes no eSocial é superior ao do Caged, ainda que se considerando as mesmas categorias de vínculos e empresas nas duas bases. Isso pode ser explicado pelo fato de que o eSocial capta melhor os vínculos temporários e, ainda, pode incluir empresas que pudessem ser omissas no Caged.

Os desligamentos, contudo, apresentaram comportamento distinto. A análise das declaraçóes por empresa, em cada uma das bases, indicou que parte das empresas estava informando as admissóes, mas não informava os desligamentos no eSocial. Dessa forma, foi construída uma série corrigida, considerando-se a informaçáo de desligamentos prestada no Caged, para as empresas que informaram apenas admissóes no eSocial, mas que também informaram desligamentos no Caged. O gráfico 3 indica a quantidade de desligamentos verificada no Caged, no eSocial e no eSocial "corrigido" após a incorporaçáo de informaçóes do Caged que não foram noticiadas no eSocial, para aquelas empresas que prestaram informaçóes aos dois sistemas. 


\section{GRÁFICO 3}

\section{Quantidade de desligamentos no Caged, no eSocial e no eSocial "corrigido" (abr./2019-dez./2019)}

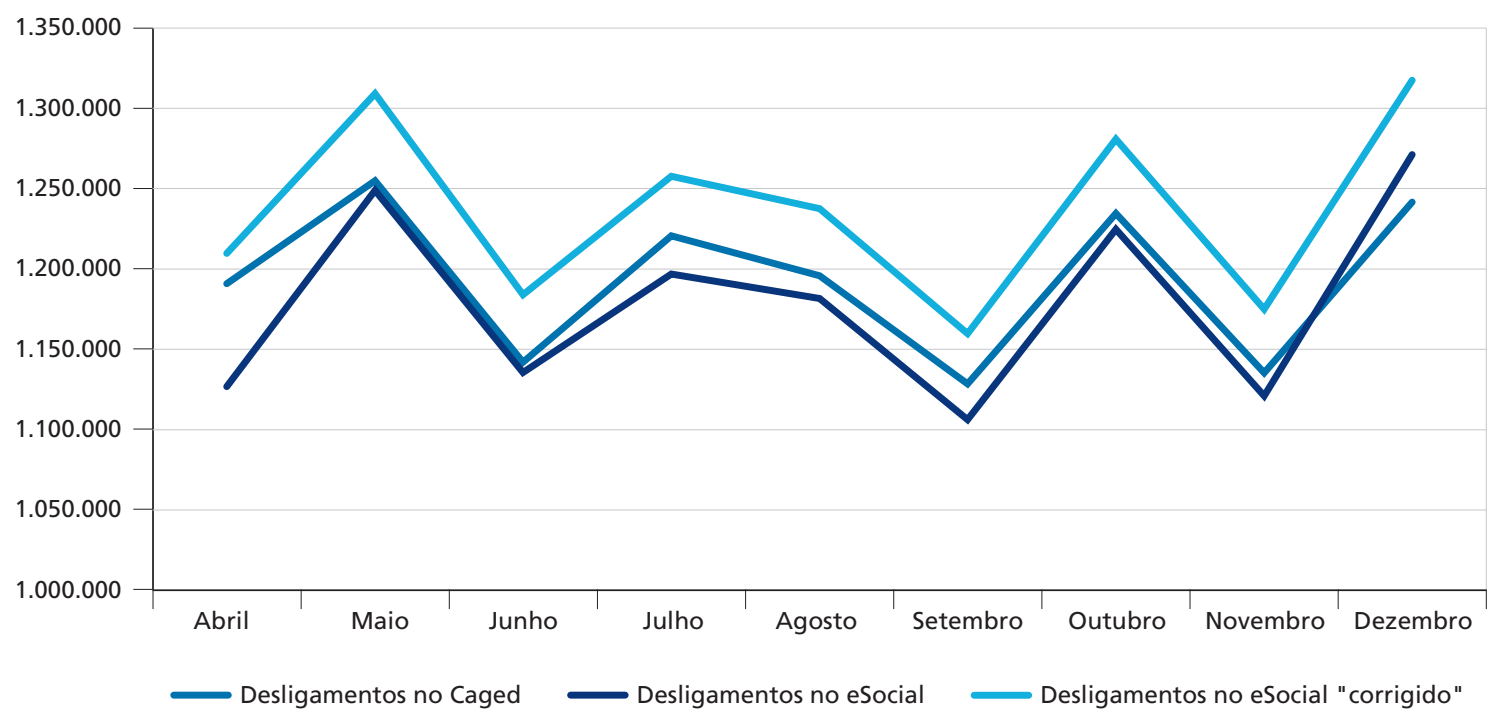

Fontes: eSocial; e Caged. Disponível em: <http://pdet.mte.gov.br/>.

De acordo com o gráfico 3, a série de desligamento do eSocial “corrigido" pela imputação dos desligamentos informados no Caged e não informados no eSocial apresenta comportamento similar ao observado no caso das admissóes, ou seja, superior ao registrado pelo Caged.

\section{NOVO CAGED A PARTIR DE 2020}

Desde janeiro de 2020, as empresas pertencentes aos grupos 1, 2 e 3 do eSocial foram desobrigadas a declarar o Caged, conforme estabelecido pela Portaria SEPRT/ME nº 1.127/2019. Permanecem obrigados a enviar o Caged somente órgãos públicos que contratam trabalhadores em regime celetista, organizaçôes internacionais e outras instituiçôes extraterritoriais.

No entanto, verificou-se a falta da prestação da informação de desligamento por parte das empresas, ainda que a Portaria $\mathrm{n}^{\mathrm{o}}$ 1.127/2019 seja clara ao estabelecer que

a obrigação da comunicação de admissóes e dispensas instituída pela Lei no 4.923, de 23 de novembro de 1965, Cadastro Geral de Empregados e Desempregados (Caged), passa a ser cumprida por meio do Sistema de Escrituração Digital das Obrigaçôes Fiscais, Previdenciárias e Trabalhistas (eSocial) a partir da competência de janeiro 2020 para as empresas ou pessoas físicas equiparadas a empresas (Brasil, 2019a).

Diante desse cenário, a SEPRT/ME elaborou um plano de ação com duas frentes. Em primeiro lugar, realizou-se um conjunto de açóes que visaram identificar a origem e a causa do problema para atuar em suas correçóes. Nesse sentido, foram realizadas açôes com intuito de comunicar as empresas e os profissionais de contabilidade acerca da 
obrigatoriedade da declaração de desligamentos ao eSocial ${ }^{13}$ e orientá-los quanto correto preenchimento das informaçóes. ${ }^{14,15}$

Cabe destacar que essas açôes foram impactadas pelo cenário de pandemia causado pela Covid-19, tendo em vista a dificuldade de comunicação com parte das empresas, que estavam fechadas ou em regime de teletrabalho durante esse período.

A segunda frente diz respeito à qualificação dos dados captados pelo eSocial e das implicaçôes técnicas das omissões observadas durante o período de transição. Nesse contexto, foram realizadas reunióes técnicas com um grupo de especialistas em mercado de trabalho para análise dos dados do emprego formal oriundos de registros administrativos, que contou com a participação de especialistas do Ipea, do Instituto Brasileiro de Geografia e Estatística (IBGE), da Fundação Getulio Vargas (FGV), da Pontifícia Universidade Católica do Rio de Janeiro (PUC-Rio), do Insper, além do próprio ME.

\subsection{Metodologia do Novo Caged a partir de 2020}

O Novo Caged é baseado no método de imputação de dados de outras fontes. Essa é uma prática comum na administração pública, visto que registros administrativos muitas vezes apresentam lacunas, como a falta de prestaçáo da informaçáo, ou inconsistências causadas por migraçóes de sistemas ao longo do seu ciclo de vida (Yaohao e Mation, 2018).

A solução encontrada segue os manuais de boas práticas no tratamento de grande volume de dados administrativos. O Serviço Federal de Processamento de Dados (Serpro), por exemplo, indica que entre as soluçôes geralmente adotadas estão a "imputação de valores, os algoritmos de expectativa e maximização, o apagamento parcial de dados, a análise completa de dados (utilizando-se muitas vezes de ferramentas de inteligência artificial neste processo) e a interpolação" (Serpro, 2018).

De forma complementar, levou-se em consideração e em análise a mitigação de possíveis riscos e limitaçóes nesse processo de imputação de outras fontes, quais sejam: a falta de compatibilidade entre variáveis; as retificaçôes realizadas em períodos distintos; a intempestividade na consolidação da informação; e a omissão ou informações prestadas incorretamente.

Para fins de imputação, optou-se por utilizar a base de dados do Empregador Web, que consiste no sistema de uso obrigatório para o preenchimento de requerimento de segurodesemprego/comunicação de dispensa de trabalhadores demitidos involuntariamente de pessoa jurídica ou pessoa física a ela equiparada. ${ }^{16}$ Assim como o Caged, o Empregador Web é um sistema criado para fins trabalhistas e está sob gestão da SEPRT/ME, de modo que há conhecimento técnico consolidado na secretaria sobre tal base.

13. Para mais informações, ver: <https://bit.ly/20nivyd $>$ e $<$ https://bit.ly/2BXKEsK>.

14. Para mais informações, ver: <https://bit.ly/38JKTUc $>$ e $<$ https://bit.ly/3fhQB2f $>$.

15. Para mais informações, ver: <https://bit.ly/2BTOByM $>$.

16. Conforme estabelecido pelas resoluções do Conselho Deliberativo do Fundo de Amparo ao Trabalhador (Codefat) nos 736/2014 e 742/2015. 
Apesar de esta imputação inicial estar restrita aos dados do Empregador Web, a SEPRT/ ME poderá realizar revisôes contínuas nessa metodologia, com vistas a avaliar a possibilidade de incorporar informaçôes de outras fontes, tendo em vista o aperfeiçoamento contínuo dos dados.

Desse modo, o processo de consolidaçáo dos dados do Novo Caged, a partir da competência de janeiro de 2020, compreende duas etapas que serão detalhadas a seguir.

1) Consolidação dos dados provenientes do eSocial e do Caged:

a) informaçóes de movimentaçóes de vínculos celetistas provenientes do eSocial para as empresas dos grupos 1, 2 e 3;

b) informaçôes de movimentaçôes de vínculos celetistas provenientes do Caged para os órgáos públicos e entidades dos grupos 4, 5 e 6;

c) informaçóes prestadas ao eSocial, na hipótese de a empresa ter prestado informaçóes em duplicidade, relativas ao mesmo período, tanto para o eSocial quanto ao Caged;

d) informaçôes do Caged, quando a empresa não prestou informação ao eSocial, apenas para fins estatísticos; $17 \mathrm{e}$

e) todas as variáveis do Caged e do eSocial foram compatibilizadas, mantendo-se o mesmo layout do Caged.

2) Imputação de desligamentos do Empregador Web:

a) a imputação dos valores de desligamentos informados no Caged por empresas que informaram zero desligamentos no eSocial e informaram desligamentos diferentes de zero no Caged;

b) a imputação dos valores de desligamentos informados no Empregador Web por empresas que informaram zero desligamentos no eSocial e não prestaram informaçóes ao Caged; e

c) a imputação é feita a partir do cruzamento por CNPJ raiz. ${ }^{18}$

As movimentaçôes do Novo Caged são, portanto, compostas das seguintes fontes:

- admissóes: eSocial e Caged; e

- desligamentos: eSocial, Caged e Empregador Web.

A tabela 1, a seguir, apresenta a análise das empresas que deixaram de prestar informação de desligamentos no eSocial entre janeiro e abril de 2020. Para realização da imputaçáo descrita anteriormente, consideraram-se as empresas que informaram zero desligamentos no eSocial. A primeira etapa consiste na verificação das declaraçóes de desligamentos dessas empresas no Caged. Para aquelas que não informaram o Caged, buscaram-se as informaçóes no Empregador Web. A última coluna da tabela expóe o total de empresas com omissáo de desligamentos no eSocial entre janeiro e abril de 2020.

17. A empresa que não informar as movimentações no eSocial está sujeita a penalidades, conforme descrito no quadro 2.

18. 0 CNPJ é composto por catorze números, sendo que os oito primeiros formam o CNPJ raiz, que identifica a empresa. Após a barra está o número de ordem do estabelecimento (matriz ou filiais) e, depois do hífen, os dois dígitos de controle. 
TABELA 1

Empresas com possibilidade de omissão de declaração nos desligamentos (jan./2020-abr./2020)

\begin{tabular}{lccccc}
\hline Competência & $\begin{array}{c}\text { Total de } \\
\text { empresas no } \\
\text { eSocial }^{1}\end{array}$ & $\begin{array}{c}\text { Empresas sem desli- } \\
\text { gamentos } \\
\text { declarados no eSocial }\end{array}$ & $\begin{array}{c}\text { Empresas sem } \\
\text { desligamentos no } \\
\text { eSocial, mas com } \\
\text { desligamentos no } \\
\text { Caged }\end{array}$ & $\begin{array}{c}\text { Empresas sem } \\
\text { desligamentos } \\
\text { no eSocial ou no } \\
\text { Caged, mas com } \\
\text { desligamentos no } \\
\text { Empregador Web }\end{array}$ & $\begin{array}{c}\text { Total de empresas com } \\
\text { omissão de desliga- } \\
\text { mentos no eSocial }\end{array}$ \\
\hline Janeiro & 654.776 & 239.569 & 12.420 & 5.373 & 17.793 \\
Fevereiro & 652.669 & 255.866 & 11.867 & 6.587 & 18.454 \\
Março & 633.362 & 212.643 & 10.534 & 6.886 & 17.420 \\
Abril $^{3}$ & 442.221 & 77.222 & 3.476 & 2.582 & 6.058 \\
\hline
\end{tabular}

Fontes: eSocial; Caged; e Empregador Web.

Notas: ${ }^{1}$ Dados do eSocial com declarações recebidas fora do prazo até 15 de maio.

2 Dados recebidos até 12 de maio.

${ }^{3}$ Consideram-se apenas as declarações no prazo.

Na tabela 2, nota-se que, de janeiro a abril de 2020, 86.757 desligamentos que não foram informados no eSocial foram declarados no Caged. Adicionalmente, 43.454 desligamentos não informados no eSocial, nem no Caged, foram declarados no Empregador Web. Desse modo, no período em análise, foi feita a imputação de 130.211 desligamentos na base de dados do eSocial. O saldo de empregos no período acumulado de janeiro a abril de 2020 passou de -633.017 para -763.228, após a imputação de dados da fonte Empregador Web.

TABELA 2

Movimentações no emprego formal, com imputação (jan./2020-abr./2020)

\begin{tabular}{lccccccc}
\hline Competência & $\begin{array}{c}\text { Total de } \\
\text { admissões } \\
\text { no eSocial }\end{array}$ & $\begin{array}{c}\text { Total de des- } \\
\text { ligamentos } \\
\text { no eSocial }\end{array}$ & $\begin{array}{c}\text { Total de } \\
\text { desligamen- } \\
\text { tos omissos } \\
\text { encontrados } \\
\text { no Caged }\end{array}$ & $\begin{array}{c}\text { Total de desliga- } \\
\text { mentos omissos } \\
\text { encontrados } \\
\text { no Empregador } \\
\text { Web }^{2}\end{array}$ & $\begin{array}{c}\text { Total de desli- } \\
\text { gamentos com } \\
\text { imputação }^{\text {nomputação }}\end{array}$ & $\begin{array}{c}\text { Saldo sem } \\
\text { imputação }\end{array}$ \\
\hline Janeiro & 1.461 .965 & 1.313 .709 & 25.469 & 9.628 & 1.348 .806 & 148.256 & 113.159 \\
Fevereiro & 1.553 .294 & 1.291 .072 & 24.833 & 12.571 & 1.328 .476 & 262.222 & 224.818 \\
Março & 1.386 .126 & 1.585 .973 & 26.478 & 14.377 & 1.626 .828 & -199.847 & -240.702 \\
Abril & 598.596 & 1.442 .244 & 9.977 & 6.878 & 1.459 .099 & -843.648 & -860.503 \\
Acumulado & 4.999 .981 & 5.632 .998 & 86.757 & 43.454 & 5.763 .209 & -633.017 & -763.228 \\
\hline
\end{tabular}

Fonte: Novo Caged.

Notas: ${ }^{1}$ Dados do eSocial com declarações recebidas fora do prazo, até 15 de maio.

2 Dados recebidos até 12 de maio.

${ }^{3}$ Consideram-se apenas as declarações no prazo. 


\subsection{Declarações fora do prazo}

No Novo Caged, consideram-se dentro do prazo as declaraçóes que foram recebidas pelo eSocial até o $15^{\circ}$ dia do mês subsequente. Cabe destacar que o percentual de declaraçóes recebidas fora do prazo no eSocial é superior à média de declaraçóes fora do prazo do Caged. Enquanto no eSocial, a média de admissóes e desligamentos que foram declarados fora do prazo foi de $7 \%$, de janeiro a abril, no Caged, a média foi de 3,6\%, em 2018. ${ }^{19}$ Esse comportamento distinto do eSocial pode ser explicado pelo período de adaptação das empresas ao cumprimento das obrigaçóes em novo sistema e tende a reduzir-se à medida que a implantação do sistema se consolide.

\section{CONSIDERAÇÕES FINAIS}

A captação das estatísticas do emprego formal está em transição em função da substituição das declaraçóes ao Caged pelo eSocial, conforme definido pela Portaria SEPRT/ME no 1.127/2019. Tal transição, ainda em curso, oferece a possibilidade histórica de aperfeiçoamento do registro administrativo e a melhora da qualidade da informação, que é essencial para a fiscalização do trabalho e para o planejamento e execução de políticas públicas. Destacam-se a maior cobertura e a tempestividade de informaçóes, que antes não estavam disponíveis ou estavam dispersas em diversos sistemas e que estão sendo unificadas em uma só ferramenta. A padronização e a desburocratização simplificam o cumprimento das obrigaçôes pelas empresas e empregadores, e a diminuição das assimetrias de informaçôes nas diferentes bases governamentais beneficiará o trabalhador conferindo maior agilidade no acesso aos direitos previdenciários e trabalhistas.

Como toda transição de sistemas informacionais, aspectos técnicos e metodológicos precisam ser comunicados. A natureza distinta de captação das informaçóes entre Caged e eSocial, ainda que suavizada pela compatibilização feita pela SEPRT/ME, apresenta implicaçóes para a análise estatística e para a comparabilidade na série histórica. Esse tipo de alteração é muito mais suscetível em registros administrativos, pelas constantes alteraçóes em normativos. Logo, não é inédita nesse ou em muitos outros registros administrativos do governo federal.

Conforme exposto nesta nota técnica, ainda que a maioria das empresas esteja obrigada a enviar o eSocial, há um natural período de adaptação à forma pela qual essas declarações são feitas no novo sistema, gerando retificação fora do prazo e falta de prestação de informaçôes durante o período de transição. A metodologia de imputação adotada para o ajuste das informaçóes prestadas ao eSocial e ao Caged visa assegurar a qualidade e a integridade das formulaçóes estatísticas a respeito do emprego formal durante a transição dessas fontes de captação de dados.

\section{REFERÊNCIAS}

BRASIL. Ministério da Economia. Portaria nº 1.127, de 14 de outubro de 2019. Define as datas e condiçôes em que as obrigaçóes de prestação de informações pelo empregador nos sistemas Caged e Rais serão substituídas pelo Sistema de Escrituração Digital das Obrigações Fiscais, Previdenciárias e Trabalhistas (eSocial). Diário Oficial, Brasília, 15 out. 2019a, p. 26. Seção 1.

19. Consideram-se os dados de 2018, pois a recepção das informações do Caged fora do prazo para 2019 ainda está em curso. 
Ministério da Economia. Portaria no 1.419, de 23 de dezembro de 2019. Dispóe sobre o cronograma de implantação do Sistema de Escrituração Digital das Obrigaçóes Fiscais, Previdenciárias e Trabalhistas (eSocial). Diário Oficial, Brasília, 24 dez. 2019b, p. 229. Seção 1.

SERPRO - SERVIÇO FEDERAL DE PROCESSAMENTO DE DADOS. Quando não é preciso preencher as lacunas. Brasília: Serpro, 2018. Disponível em: <https://bit.ly/3gOTLLs $>$.

YAOHAO, P.; MATION, L. F. O desafio do pareamento de grandes bases de dados: mapeamento de métodos de record linkage probabilístico e diagnóstico de sua viabilidade empírica. Rio de Janeiro: Ipea, 2018. (Texto para Discussáo, n. 2420). 


\section{ANEXO A}

TABELA A. 1

Movimentações Caged - Brasil (2019)

\begin{tabular}{lcc}
\hline Mês & Admissões & Desligamentos \\
\hline Abril & 1.316 .137 & 1.190 .890 \\
Maio & 1.264 .648 & 1.254 .936 \\
Junho & 1.178 .842 & 1.142 .010 \\
Julho & 1.266 .274 & 1.220 .518 \\
Agosto & 1.325 .967 & 1.195 .703 \\
Setembro & 1.286 .120 & 1.128 .411 \\
Outubro & 1.311 .885 & 1.234 .629 \\
Novembro & 1.246 .382 & 1.135 .248 \\
Dezembro & 958.477 & 1.241 .545 \\
\hline
\end{tabular}

Obs.: Caged - Cadastro Geral de Empregados e Desempregados. Disponível em: <http://pdet.mte.gov.br/>.

TABELA A.2

Movimentações eSocial - Brasil (2019)

\begin{tabular}{lcccccc}
\hline Mês & $\begin{array}{c}\text { Quantidade de } \\
\text { empresas }\end{array}$ & Admissões & Desligamentos & $\begin{array}{c}\text { Quantidade de } \\
\text { empresas com } \\
\text { omissão de } \\
\text { desligamentos }\end{array}$ & $\begin{array}{c}\text { Quantidade de } \\
\text { desligamentos } \\
\text { omissos }\end{array}$ & $\begin{array}{c}\text { Desligamentos } \\
\text { eSocial } \\
\text { "corrigido" }\end{array}$ \\
\hline Abril & 658.337 & 1.401 .644 & 1.126 .803 & 43.456 & 82.808 & 1.209 .611 \\
Maio & 671.763 & 1.353 .803 & 1.248 .907 & 27.739 & 60.122 & 1.309 .029 \\
Junho & 632.265 & 1.255 .282 & 1.135 .550 & 22.700 & 48.535 & 1.184 .085 \\
Julho & 659.767 & 1.330 .105 & 1.196 .814 & 25.639 & 60.788 & 1.257 .602 \\
Agosto & 668.522 & 1.390 .810 & 1.181 .675 & 25.345 & 55.774 & 1.237 .449 \\
Setembro & 641.829 & 1.348 .118 & 1.106 .231 & 23.400 & 53.520 & 1.159 .751 \\
Outubro & 662.771 & 1.393 .446 & 1.224 .679 & 24.905 & 56.195 & 1.280 .874 \\
Novembro & 615.960 & 1.329 .856 & 1.120 .979 & 23.030 & 54.095 & 1.175 .074 \\
Dezembro & 550.335 & 1.043 .082 & 1.271 .160 & 17.765 & 46.342 & 1.317 .502 \\
\hline
\end{tabular}

Obs.: eSocial - Sistema de Escrituração Digital das Obrigações Fiscais, Previdenciárias e Trabalhistas. Disponível em: $<$ http://pdet.mte.gov.br/>. 